\title{
Partitioning of the contributions of rib cage and abdomen to ventilation in ankylosing spondylitis
}

\author{
GUNNAR GRIMBY,AXEL R. FUGL-MEYER, \\ and A N N B L M T R A N \\ Departments of Rehabilitation Medicine and Clinical Physiology, University of Göteborg, \\ Göteborg, Sweden
}

\begin{abstract}
Grimby, G., Fugl-Meyer, A. R., and Blomstrand, A. (1974). Thorax, 29, 179-184. Partitioning of the contributions of rib cage and abdomen to ventilation in ankylosing spondylitis. The relative contributions of the rib cage and abdomen to ventilation were studied in the sitting position in patients with ankylosing spondylitis, using measurements of changes in the anteroposterior diameters. The functional impairment of the spine and adjacent joints was also evaluated. In most patients vital capacity and total lung capacity were reduced, but functional residual capacity was normal. The relative contribution of the rib cage to ventilation was reduced at rest compared to normal subjects, and decreased further during hyperventilation induced by rebreathing. The end-expiratory level of the abdomen decreased more markedly during hyperventilation than in normal subjects and even the end-inspiratory level of the abdomen increased somewhat. The findings are consistent with a reduced mobility of the ribs and a greater than normal excursion of the diaphragm during breathing.
\end{abstract}

Ankylosing spondylitis is a chronic inflammatory disease primarily affecting the spine and adjacent joints. It is generally first recognized in the sacroiliac joints and usually progresses in the cranial direction. Ventilatory function may be impaired by the inflammatory process in sternocostal, costovertebral, and thoracic spine joints. The process may result in ankylosis and reduced mobility of the thorax. Jordanoglou (1969), using a special instrument to measure rib movements, found reduced mobility of the ribs in patients with ankylosing spondylitis. Thus, at least in advanced cases, the vital capacity and total lung capacity are reduced while residual volume and functional residual capacity are usually higher than the predicted normal values (Rogan, Needham and McDonald, 1955; Travis et al., 1960; Zorab, 1962; Hart, Emerson, and Gregg, 1963; Sharp et al., 1964). Total and chest wall compliance are decreased, whereas lung compliance is normal in most patients (Hart et al., 1963; Sharp et al., 1964). In an earlier study (Travis et al., 1960) reduced elastic recoil of the lungs at resting mid-position was found.

The separate functions of the rib cage and the diaphragm have not been evaluated in detail.
Josenhans, Wang, Josenhans, and Woodbury (1971) recently showed an increased diaphragmatic contribution to the tidal volume in patients with ankylosing spondylitis as compared to that of normal subjects For their investigation they applied a modified ballistographic method (Josenhans and Wang, 1970) by which the linear momentum of breathing is measured. Measurements by this technique can only be obtained in the supine position.

In the present study another principle has been applied to determine the relative contribution of the rib cage and abdomen to ventilation, measurements being made in the sitting position. The technique of Konno and Mead (1967), modified by Mead, Peterson, Grimby, and Mead (1967), was used to record the anteroposterior diameter changes of the rib cage and abdomen. Using this technique, these authors showed that changes in both the abdomen and rib cage were nearly linearly related to their volume changes. The relationship between diameter and volume changes can be obtained by having the subjects perform so-called isovolume manoeuvres. The technique has been used in normal subjects (Grimby, Bunn, and Mead, 1968), in patients with tetraplegia 
(Fugl-Meyer and Grimby, 1971), and in patients with obstructive lung disease (Grimby, Elgefors, and Oxhöj, 1973). In addition to the ventilatory studies, the functional impairment of the spine and adjacent joints was evaluated.

\section{PATIENTS}

Eight male patients with clinically established ankylosing spondylitis were studied. The duration of symptoms was 3 to 20 years (average 10 years). Four of the patients complained of dyspnoea on exertion, and five had thoracic joint pain on deep inspiration. For classification of dyspnoea on exertion the questionnaire concerning respiratory symptoms approved by The College of General Practitioners (1961) was used. Details are recorded in Table I.

\section{T A B L E I}

PHYSICAL CHARACTERISTICS AND RESPIRATORY SYMPTOMS OF EIGHT PATIENTS WITH ANKYLOSING SPONDYLITIS

\begin{tabular}{l|ccccc}
\hline Patient & $\begin{array}{c}\text { Age } \\
\text { (yr) }\end{array}$ & $\begin{array}{c}\text { Height } \\
\text { (cm) }\end{array}$ & $\begin{array}{c}\text { Weight } \\
\text { (kg) }\end{array}$ & $\begin{array}{c}\text { Degree of } \\
\text { Dyspnoea }\end{array}$ & $\begin{array}{c}\text { Smoking Habit } \\
\text { (cigarettes/day) }\end{array}$ \\
\cline { 2 - 6 } M.A. & 58 & 176 & 82 & I & 0 \\
S.A. & 39 & 193 & 76 & II & $5-14$ \\
K.E. & 27 & 175 & 55 & II & $1-4$ \\
L.E. & 22 & 179 & 68 & I & 0 \\
B.H. & 43 & 178 & 57 & II & $15-24$ \\
A.K. & 41 & 178 & 71 & I & 0 \\
J.L. & 46 & 179 & 75 & I & 0 \\
E.O. & 37 & 170 & 45 & III & 0 \\
\hline
\end{tabular}

1 I No complaints.

II Dyspnoea on walking fast or uphill.

III Dyspnoea on accompanied walking at normal speed on level ground.

\section{METHODS}

The functional residual capacity (FRC) was determined with the patient in the sitting position using the helium dilution technique, and the subdivisions of the total lung capacity (TLC) were measured. Dynamic spirometry with measurement of the forced expired volume in one second $\left(\mathrm{FEV}_{1}\right)$ was performed with a modified Bernstein spirometer. For prediction of normal values, the formulae of Berglund et al. (1963) and Grimby and Söderholm (1963) were used.

The anteroposterior diameter variations of the rib cage and the abdomen were measured applying two pairs of magnetometers (Mead et al., 1967). An anteriorly placed coil generated an electromagnetic field, and posteriorly a receiver coil was tuned to the generating frequency. Two pairs of coils, tuned to different frequencies, were taped to the body surface in the midline at the nipple and umbilical levels respectively. The output of each pair of magnetometers was fed to a direct-writing Mingograph and to an X-Y recorder (Bryans type 22020, Crawley, England). The relationship between linear motion and volume change of the two parts of the chest wall was defined by a series of isovolume manoeuvres produced at different lung volumes which the patients were able to learn during a relatively short period of instruction and practice (Konno and Mead, 1967). In these manoeuvres, the patient first contracts his abdominal muscles while simultaneously expanding his 흠 rib cage, thus displacing volume from the abdomen $\frac{\bar{p}}{\bar{p}}$ into the rib cage. He then relaxes his abdominal $\mathbb{D}$ muscles and depresses his rib cage, thus displacing volume from the rib cage into the abdomen. $X-Y$ is tracings of rib cage versus abdominal anteroposterior $\vec{\circ}$ diameters for isovolume manoeuvres at different lung volumes produce nearly parallel flatloops (Fig. 1). $\bar{\omega}$

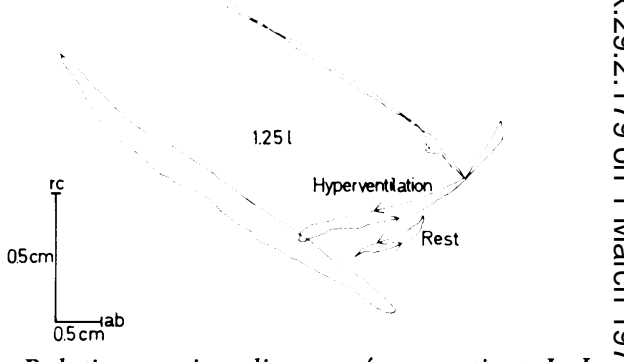

FIG. 1. Relative motion diagram from patient J. L. $\rightarrow$ displaying motion of the rib cage (rc, y-axis) and the abdomen $(a b, x$-axis) at rest and after about 20 minutes of induced hyperventilation. Increase in the anteroposterior diameters (inspiration) is upwards and $\bar{\partial}$ to the right. The broken lines show the isovolume relationship at two lung volumes. The expired volume $\stackrel{\mathbb{Q}}{\stackrel{2}{2}}$ between the two isovolume manoeuvres is $1.25 l$.

The volume-diameter relationship for the rib cage was obtained graphically by noting the diameter and volume changes at constant abdominal diameter and that for the abdomen by making the corresponding comparison at constant rib cage diameter. In half the patients, however, the relationship between linear $\tilde{x}$ motion and volume change for the rib cage, calcu- 0 lated from the isovolume manoeuvres, did not give acceptable values for volume partitioning during $\delta$ breathing. However, in all the patients (as in the normal subjects), the abdomen lagged behind the ribo cage during both tidal breathing and isovolume manoeuvres. As the rib cage and abdomen make up the two parts of the chest wall, the volume changes of the rib cage could be calculated as the total volume N changes measured spirometrically (Electro-Med 780, Houston, Texas) minus the calculated volume changes 0 of the abdomen.

Measurements were performed with the patiento sitting erect on a chair at rest. The chest was unclothed and care was taken that clothing did not? restrict the abdominal movements. The diametero changes were recorded simultaneously with the spirometer volume changes during spontaneous breathing $\frac{0}{0}$ and during hyperventilation induced by rebreathing $\underset{\mathbb{C}}{\stackrel{O}{*}}$ without $\mathrm{CO}_{2}$ absorber or extra oxygen supply to the closed circuit. The hyperventilation continued until $\mathbb{\Phi}_{\mathcal{Q}}$ the patient noted marked discomfort for at least 2 tog 3 minutes. 
The physical examination included:

Inspection of the spine. Thoracic kyphosis was graded from 0 to 3 .

Inspection of thoracolumbar mobility. Movements were tested in sagittal, frontal, and transverse planes. Grading was from 0 (normal mobility) to 3 (ankylosis).

Palpatation in the prone position for spinalinterspinal tenderness, with grading from 0 (none) to 3 (very marked).

The costovertebral and costosternal joints were palpated for tenderness in the sitting position and graded as above.

\section{RESULTS}

The observation of joint involvement (Table II) revealed tenderness corresponding to the costovertebral and/or costosternal joints in five

T A B L E I I

PHYSICAL EXAMINATION

\begin{tabular}{l|cccc}
\hline & $\begin{array}{c}\text { Reduced } \\
\text { Patient }\end{array}$ & $\begin{array}{c}\text { Thoracic } \\
\text { Kyphosis } \\
\text { lumbar } \\
\text { Mobility }\end{array}$ & $\begin{array}{c}\text { Spinal- } \\
\text { interspinal } \\
\text { Tenderness }\end{array}$ & $\begin{array}{c}\text { Costovertebral } \\
\text { Costosternal } \\
\text { Tenderness }\end{array}$ \\
\hline M.A. & 2 & 1 & 1 & 0 \\
S.A. & 1 & 3 & 3 & 1 \\
K.E. & 1 & 2 & 2 & 2 \\
L.E. & 2 & 0 & 0 & 2 \\
B.H. & 3 & 3 & 0 & 0 \\
A.K. & 3 & 2 & 3 & 2 \\
J.L. & 3 & 3 & 3 & 2 \\
E.O. & 3 & 3 & & \\
\hline
\end{tabular}

For grading see text.

patients. All patients except one had restricted thoracolumbar mobility; four patients were virtually ankylotic.

In most patients the vital capacity and total lung capacity (Table III) were reduced, but with normal or only slightly decreased values in the two patients with little or no pain or no obvious impairment of thoracolumbar mobility. Functional residual capacity and residual volume showed no systematic deviation from the predicted normal values. Dynamic spirometry did not reveal evidence of airway obstruction.

The relative contribution of the rib cage (Table IV) varied between individuals. This may depend on anthropometric differences but also on different degrees of impairment of rib cage mobility. There was, however, no obvious correlation between the findings at the physical examination (Table II) and the ventilation partitioning of the rib cage. The relative contribution of the rib cage to tidal volume, which in normals is around $75 \%$ in the sitting position and increases somewhat during induced hyperventilation (Grimby, Goldman, and Mead, 1971), was in all but two patients below that value with a mean value of $56 \%$. With hyperventilation to an average of $37 \mathrm{l} . / \mathrm{min}$ (tidal volume being $46 \%$ of the vital capacity) it decreased further to a mean of $46 \%$, although the volume changes of the rib cage increased. The excursions of the anteroposterior diameter of the rib cage averaged $0.39 \mathrm{~cm}$ at rest with a tidal volume of 0.611 . This is a substantially lower value than in a group of young normal subjects where the average anteroposterior diameter variation at the same level was $0.74 \mathrm{~cm}$ at a tidal volume of 0.841 . (Bake, Grimby, and Hoskins, unpublished observations). The average a-p diameter increased at hyperventilation $160 \%$ for the rib cage and $215 \%$ for the abdomen respectively.

In the relative motion diagram of the rib cage and the abdomen (Fig. 1) there is a marked reduction of the end-expiratory volume of the abdomen during hyperventilation (shift to the left) but only a slight decrease in the endexpiratory volume of the rib cage. The endinspiratory volumes of both the rib cage and the abdomen were increased (shifts upwards and to the right, respectively).

T A B L E I I I

RESULTS OF STATIC AND DYNAMIC SPIROMETRY

\begin{tabular}{|c|c|c|c|c|c|c|c|c|c|c|c|}
\hline Patient & $\begin{array}{l}\text { VC } \\
\text { (1.) }\end{array}$ & $\%$ Pred. & $\begin{array}{c}\text { TLC } \\
\text { (1.) }\end{array}$ & $\%$ Pred. & $\begin{array}{c}\text { FRC } \\
\text { (1.) }\end{array}$ & $\%$ Pred. & $\begin{array}{l}\text { RV } \\
\text { (l.) }\end{array}$ & $\%$ Pred. & $\underset{\text { (1.) }}{\text { FEV }_{1}}$ & $\%$ Pred. & FEV $\%$ \\
\hline $\begin{array}{l}\text { M.A. } \\
\text { S.A. } \\
\text { K.E. } \\
\text { L.E. } \\
\text { B.H. } \\
\text { A.K. } \\
\text { J.L. } \\
\text { E.O. }\end{array}$ & $\begin{array}{l}4 \cdot 43 \\
4 \cdot 64 \\
3 \cdot 30 \\
4 \cdot 74 \\
2 \cdot 22 \\
3 \cdot 57 \\
2 \cdot 73 \\
2 \cdot 14\end{array}$ & $\begin{array}{l}98 \\
79 \\
65 \\
88 \\
45 \\
73 \\
54 \\
46\end{array}$ & $\begin{array}{l}7 \cdot 05 \\
6 \cdot 51 \\
4 \cdot 77 \\
6 \cdot 35 \\
5 \cdot 21 \\
5 \cdot 74 \\
3 \cdot 82 \\
4 \cdot 52\end{array}$ & $\begin{array}{r}109 \\
81 \\
69 \\
92 \\
71 \\
86 \\
57 \\
68\end{array}$ & $\begin{array}{l}4 \cdot 14 \\
3 \cdot 91 \\
2 \cdot 70 \\
3 \cdot 56 \\
4 \cdot 17 \\
3 \cdot 50 \\
2 \cdot 36 \\
3 \cdot 22\end{array}$ & $\begin{array}{r}128 \\
90 \\
72 \\
104 \\
103 \\
103 \\
72 \\
86\end{array}$ & $\begin{array}{l}2.81 \\
1.92 \\
1.62 \\
2.05 \\
3.02 \\
2.36 \\
1.30 \\
2.38\end{array}$ & $\begin{array}{r}142 \\
92 \\
96 \\
139 \\
147 \\
134 \\
81 \\
129\end{array}$ & $\begin{array}{l}3.07 \\
3.93 \\
3.09 \\
4.43 \\
2.06 \\
3.21 \\
2.73 \\
1.89\end{array}$ & $\begin{array}{r}98 \\
88 \\
75 \\
100 \\
56 \\
86 \\
69 \\
52\end{array}$ & $\begin{array}{r}69 \\
85 \\
94 \\
93 \\
93 \\
90 \\
100 \\
97\end{array}$ \\
\hline $\begin{array}{l}\text { Mean } \\
\text { SD }\end{array}$ & $\begin{array}{l}3.47 \\
1.06\end{array}$ & $\begin{array}{l}69 \\
20\end{array}$ & $\begin{array}{l}5 \cdot 50 \\
1 \cdot 11\end{array}$ & $\begin{array}{l}79 \\
16\end{array}$ & $\begin{array}{l}3.45 \\
0.66\end{array}$ & $\begin{array}{l}95 \\
19\end{array}$ & $\begin{array}{l}2 \cdot 18 \\
0.58\end{array}$ & $\begin{array}{r}120 \\
26\end{array}$ & $\begin{array}{l}3.05 \\
0.86\end{array}$ & $\begin{array}{l}78 \\
18\end{array}$ & $\begin{array}{l}90 \\
10\end{array}$ \\
\hline
\end{tabular}

$\mathrm{FEV} \%=\left(\mathrm{FEV}_{1} / \mathrm{VC}\right) \times 100$ 

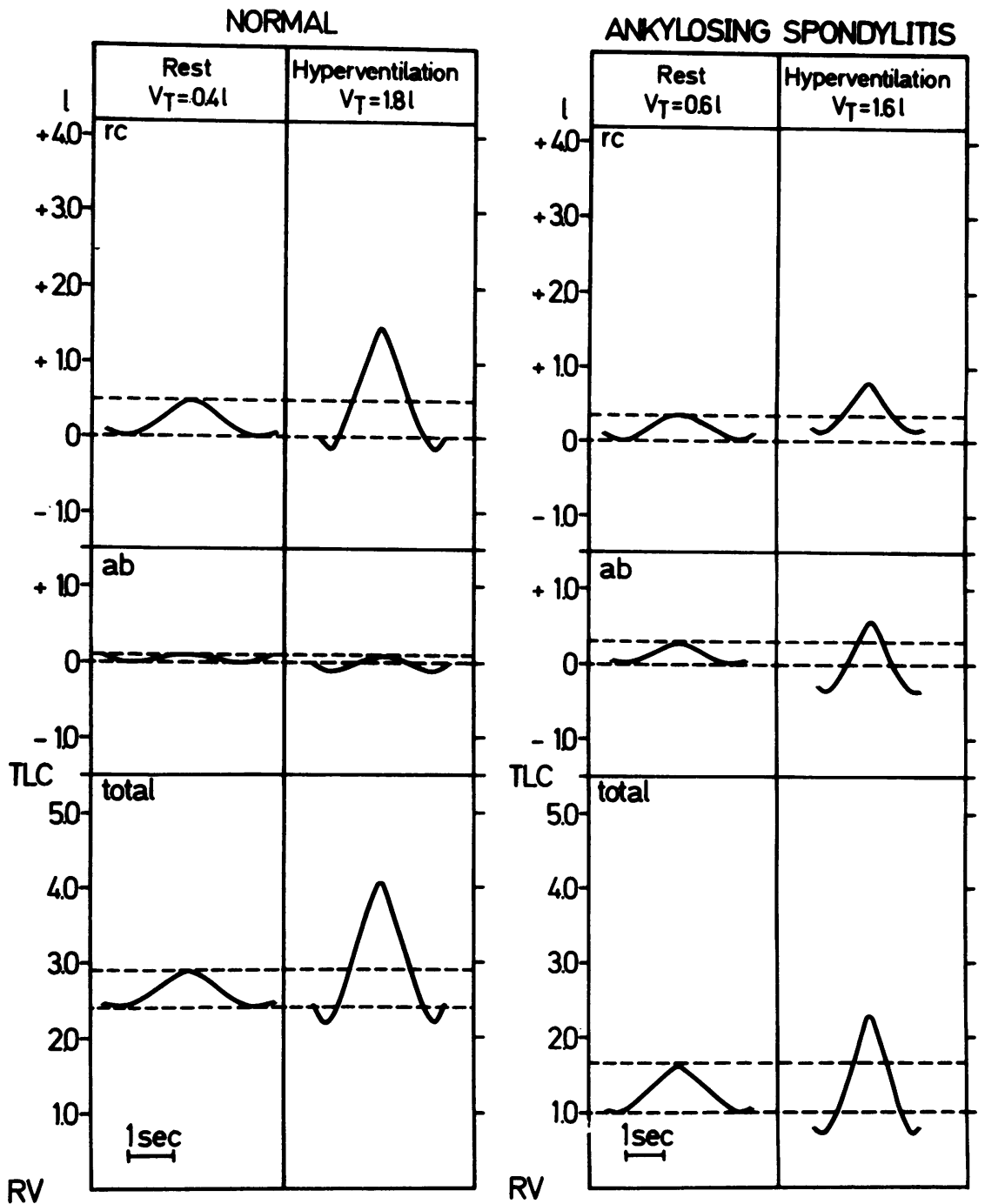

FIG. 2. Tidal ventilation at rest and during hyperventilation in normal male subjects aged 32-47 (Grimby et al., 1971) and patients with ankylosing spondylitis. The relative contributions of rib cage (top) and abdomen (middle) to the overall ventilation (bottom) are shown. Broken lines indicate the resting end-expiratory and end-inspiratory levels. 
T A B L E I V

RESPIRATORY FREQUENCY (f), TIDAL VOLUME (VT), RELATIVE CONTRIBUTION OF RIB CAGE TO TIDAL VOLUME $\left(\frac{V_{T r} \times 100}{V T}\right)$, AND ANTEROPOSTERIOR (a-p) AMPLITUDE OF RIB CAGE (rc) AND ABDOMEN (ab) AT REST AND DURING INDUCED HYPERVENTILATION

\begin{tabular}{|c|c|c|c|c|c|c|c|c|c|c|}
\hline \multirow[b]{3}{*}{ Patient } & \multicolumn{5}{|c|}{ Rest } & \multicolumn{5}{|c|}{ Hyperventilation } \\
\hline & \multirow[b]{2}{*}{$\mathbf{f}$} & \multirow{2}{*}{$\begin{array}{l}\text { VT } \\
(1 .)\end{array}$} & \multirow{2}{*}{$\frac{V_{T r c} \times 100}{V T}$} & \multicolumn{2}{|c|}{$\begin{array}{l}\text { a-p amplitude } \\
\text { (cm) }\end{array}$} & \multirow[b]{2}{*}{ f } & \multirow{2}{*}{$\begin{array}{l}\text { VT } \\
\text { (1.) }\end{array}$} & \multirow{2}{*}{$\frac{V_{T r c} \times 100}{V T}$} & \multicolumn{2}{|c|}{$\underset{\text { (cm) }}{\text { a-p amplitude }}$} \\
\hline & & & & rc & $a b$ & & & & rc & $\mathbf{a b}$ \\
\hline $\begin{array}{l}\text { M.A. } \\
\text { S.A. } \\
\text { K.E. } \\
\text { L.E. } \\
\text { B.H. } \\
\text { A.K. } \\
\text { J.L. } \\
\text { E.O. }\end{array}$ & $\begin{array}{l}11 \\
26 \\
14 \\
19 \\
16 \\
18 \\
18 \\
24\end{array}$ & $\begin{array}{l}0.86 \\
0.68 \\
0.57 \\
0.58 \\
0.61 \\
0.37 \\
0.62 \\
0.63\end{array}$ & $\begin{array}{l}36 \\
84 \\
71 \\
63 \\
45 \\
52 \\
51 \\
45\end{array}$ & $\begin{array}{l}\overline{0.36} \\
0.38 \\
0.51 \\
0.40 \\
\overline{0.23} \\
0.43\end{array}$ & $\begin{array}{l}\overline{0.43} \\
0.34 \\
0.87 \\
0.95 \\
\overline{0.76} \\
0.71\end{array}$ & $\begin{array}{l}16 \\
24 \\
19 \\
21 \\
21 \\
21 \\
33 \\
32\end{array}$ & $\begin{array}{l}2.23 \\
1.22 \\
1.39 \\
1.73 \\
1.41 \\
1.76 \\
1.68 \\
1.45\end{array}$ & $\begin{array}{l}37 \\
67 \\
66 \\
46 \\
38 \\
38 \\
45 \\
29\end{array}$ & $\begin{array}{l}\overline{1.03} \\
1.32 \\
1.30 \\
0.78 \\
\overline{0.50} \\
-\end{array}$ & $\begin{array}{l}1.25 \\
1.47 \\
0.93 \\
3.82 \\
2.22 \\
-.17 \\
-\end{array}$ \\
\hline $\begin{array}{l}\text { Mean } \\
\text { SD }\end{array}$ & $\begin{array}{r}18 \\
5\end{array}$ & $\begin{array}{l}0.61 \\
0.13\end{array}$ & $\begin{array}{l}56 \\
16\end{array}$ & $\begin{array}{l}0.39 \\
0.09\end{array}$ & $\begin{array}{l}0.68 \\
0.24\end{array}$ & $\begin{array}{r}23 \\
6\end{array}$ & $\begin{array}{l}1 \cdot 60 \\
0 \cdot 31\end{array}$ & $\begin{array}{l}46 \\
14\end{array}$ & $\begin{array}{l}0.99 \\
0.35\end{array}$ & $\begin{array}{l}1.98 \\
1.04\end{array}$ \\
\hline
\end{tabular}

The decrease of the end-expiratory volume of the abdomen during hyperventilation, which was seen in all patients, was more marked than in normal subjects (Fig. 2). In all but one patient there was a slight increase of the end-expiratory volume of the rib cage.

\section{DISCUSSION}

We are in agreement with Josenhans et al. (1971) in finding an increased relative contribution of the diaphragm-abdomen to ventilation in patients with anykylosing spondylitis. However, they studied their subjects in the supine position, where the diaphragm-abdomen even in normal subjects contributes proportionately more to the tidal volume than in the upright position (Konno and Mead, 1967; Fugl-Meyer, 1974). In the present study, the principles of Konno and Mead (1967) for measuring the relative volume partitioning of the rib cage and the diaphragm-abdomen were applied and emphasis was placed on an analysis of the shifts in the respiratory positions of these two parts of the chest wall.

Attempts were made to obtain the static pressure-volume characteristics of the rib cage and the abdomen, but reproducible recordings of 'relaxed' expiration (Konno and Mead, 1967) could not be obtained. Thus, we do not know to what extent these patients breathe along the relaxed characteristics at rest, as normal persons tend to do in the sitting position (Mead, Goldman, and Grimby, 1971). Already at relatively moderate hyperventilation there is, however, clear evidence of active expiration by the abdomen, the relative contribution of the diaphragm-abdomen to the ventilation thus being increased. This means increased craniocaudal motion of the diaphragmatic dome compared to normal subjects. It is interesting to note that the increased diaphragmatic motion is occurring in both the expiratory and inspiratory directions. In normal subjects (Grimby et al., 1968; Grimby et al., 1971), as well as in patients with obstructive lung disease (Grimby et al., 1973), the increased motion tends to be almost entirely in the expiratory direction, thus allowing the diaphragm to work within its optimal range (Pengelly, Alderson, and MilicEmili, 1971). In patients with ankylosing spondylitis the increased motion of the diahragmabdomen can be assumed to compensate for the reduced mobility of the rib cage. At increased ventilatory rates the muscles of the rib cage cannot to the same extent as in normal subjects (Mead et al., 1971) take over the job of elevating and expanding the ribs. The diaphragm then has to function over a mechanically less favourable range where the volume change for unit muscular effort may be reduced.

There are several possible explanations for the reduction of the respiratory motion of the rib cage. Some of the more important features are probably decreased compliance (Hart et al., 1963; Sharp et al., 1964), impaired intercostal muscle function (Josenhans et al., 1971), which in its turn may result both from muscular atrophy and from sternocostal and costovertebral contractures leading to inadequate information from jointreceptors (Godwin-Austen, 1969) and thus to changes in the central nervous regulation of respiratory muscle function (von Euler, 1966).

From the therapeutic point of view our findings suggest that exercises to maintain the rib cage mobility at an early stage of the disease may be beneficial for ventilatory function. The possibility of increasing the lung volume at a more chronic 
stage is probably limited, at least over a short period of treatment (Blomstrand, Fugl-Meyer, and Grimby, 1973).

The study was supported by grants from the Swedish Association against Rheumatism and the Swedish Medical Research Council (project No. B 73-14x-3888-01).

\section{REFERENCES}

Berglund, E., Birath, G., Bjure, J., Grimby, G., Kjellmer, I., Sandqvist, L., and Söderholm, B. (1963). Spirometric studies in normal subjects. I. Forced expirograms in subjects between 7 and 70 years of age. Acta Medica Scandinavica, 173, 185 .

Blomstrand, A., Fugl-Meyer, A. R., and Grimby, G. (1973). Respiratory impairment and exercise tolerance in patients with ankylosing spondylitis. (In preparation).

College of General Practitioners (1961). Chronic bronchitis in Great Britain. British Medical Journal, 2, 973.

Euler, C. von (1966). Proprioceptive control in respiration. In Muscular Afferents and Motor Control; Proceedings 1st Nobel Symposium, 1965, Stockholm, edited by R. Granit. Almqvist and Wiksell, Stockholm.

Fugl-Meyer, A. R. (1974). On postural and sexual differences in breathing patterns. Respiration (In press).

— and Grimby, G. (1971). Rib-cage and abdominal volume ventilation partitioning in tetraplegic patients. Scandinavian Journal of Rehabilitation Medicine, 3, 161.

Godwin-Austen, R. B. (1969). The mechanoreceptors of the costovertebral joints. Journal of Physiology, 202, 737.

Grimby, G., Bunn, J., and Mead, J. (1968). Relative contribution of rib-cage and abdomen to ventilation during exercise. Journal of Applied Physiology, 24, 159.

_- Elgefors, B., and Oxhöj, H. (1973). Ventilatory levels and chest wall mechanics during exercise in obstructive lung disease. Scandinavian Journal of Respiratory Diseases, 54, 45.

—_, Goldman, M., and Mead, J. (1971). Rib-cage and abdominal volume partitioning during exercise and induced hyperventilation. Scandinavian Journal of Respiratory Diseases, Suppl. 77, 4. and Söderholm, B. (1963). Spirometric studies in normal subjects. III. Static lung volumes ando maximum voluntary ventilation in adults with a음

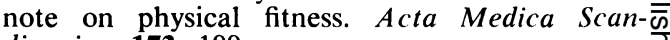
dinavica, 173, 199.

Hart, F. D., Emerson, P. A., and Gregg, I. (1963) Thorax in ankylosing spondylitis. Annals of the w Rheumatic Diseases, 22, 11.

Josenhans, W. T. and Wang, C. S. (1970). A modified ballistic method for measuring axial mass dis- $\vec{\omega}$ placement caused by breathing. Journal of Applied Physiology, 28, 679.

- $\frac{}{1971)}$, Josenhans, G., and Woolbury, J. F. L. (1971). Diaphragmatic contribution to ventilation in patients with ankylosing spondylitis. Respira-iv tion, 28, 331 .

Jordanoglou, J. (1969). Rib movements in health, kyphoscoliosis, and ankylosing spondylitis. Thorax, 24, 407.

Konno, K. and Mead, J. (1967). Measurement of the separate volume changes of rib cage and abdomen during breathing. Journal of Applied Physiology, $\stackrel{\bigcirc}{\supset}$ 22, 407.

Mead, J., Goldman, M., and Grimby, G. (1971).

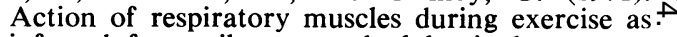
inferred from rib-cage and abdominal pressure-volume partitioning. Scandinavian Journal of Respiratory Diseases, Suppl. 77, 8.

, Peterson, N., Grimby, G., and Mead, J. (1967). Pulmonary ventilation measured from body sur-응 face movements. Science, 156, 1383.

Pengelly, L. D., Alderson, A. M., and Milic-Emili, J. $\overrightarrow{\vec{D}}$ (1971). Mechanics of the diaphragm. Journal of 3 Applied Physiology, 30, 797.

Rogan, M. C., Needham, C. D., and McDonald, I.0 (1955). Effect of ankylosing spondylitis on ventilatory function. Clinical Science, 14, 91.

Sharp, J. T., Sweany, S. K., Henry, J. P., Pietras, R. 임 J., Meadows, W. R., Amaral, E., and Rubinstein, $\underset{x}{ }$ H. M. (1964). Lung and thoracic compliances in ankylosing spondylitis. Journal of Laboratory and Clinical Medicine, 63, 254.

Travis, D. M., Cook, C. D., Julian, D. G., Crump, C. H., Helliesen, P., Robin, E. D., Bayles, T. B., o and Burwell, C. S. (1960). The lungs in rheumatoid spondylitis. Gas exchanges and lung $D$ mechanics in a form of restrictive pulmonary을. disease. American Journal of Medicine, 29, 623.

Zorab, P. A. (1962). The lungs in ankylosing spondy-o litis. Quarterly Journal of Medicine, 31, 267.

Requests for reprints to: Dr. G. Grimby, Department of Rehabilitation Medicine, Sahlgren's Hospital, S-413 45 Göteborg, Sweden. 